3. Платон. Теэтет // Платон. Соч. : в 4 т. М., 1993. T. 2. C. $192-275$.

4. Лейбнии Г. В. Монадология : соч. : в 4 т. М., 1982. T. 1. C. 413-429.

5. Пушкин А. С. Евгений Онегин. М., 1981. 255 с.

6. Августин Аврелий. Исповедь. М., 1991. 488 с.

7. Декарт Р. Размышления о первой философии // Декарт Р. Соч. : в 2 т. М., 1994. Т. 2. С. 3-72.

8. Погоняйло А. Г. История и дефиниция (к вопросу об исторических формах философии) // Философия истории философии : обязательность и навязчивость исторического. СПб., 2012. С. 33-49.

\section{Once Again on Two Metaphors of Memory}

\section{E. V. Malyshkin}

St.-Petersburg State University

7-9, Universitetskaya quay., St.-Petersburg, 199034, Russia

E-mail: malyshkin@narod.ru

The article explains the manner to think on two metaphors of memory: a track and a project. The content of these metaphors is clarified. Metaphor of track contains at least two stable meanings: strength and (stability, depth of the track) and beginningless. These meanings we can find inasmuch as in texts of ancient thinkers as in Early modern authors. It also reveals the connection of these metaphors with the notions of body, of machine memory, of finite and infinite account, with prudentia and meditatio notions of Cartesian metaphysics. The difference between a perfect body and the ascetic body is determed in st. Augustine's analyses of memory and oblivion. In conclusion of the paper the difference between good and bad memories is accentuated. Key words: memory, memory machines, memory metaphors.

УДК 130.3

\section{ЧЕЛОВЕЧНОСТЬ КАК ВЫРАЖЕНИЕ ДУХОВНОГО БЫТИЯ ЧЕЛОВЕКА}

\author{
Мокин Борис Иванович - \\ доктор философских наук, профессор кафедры \\ теоретической и социальной философии, \\ Саратовский государственный университет \\ E-mail: boris.mokin2014@yandex.ru
}

Предметом анализа в статье являются ощущения, которые рассматриваются как репрезентанты внешнего мира во внутреннем бытии человека. В силу этого они выступают основой не только познания человека, как полагают многие исследователи, но и всего духовного бытия. Ощущения обладают информационной и оценивающей функциями. Первая обусловливает сферу знания, на чем традиционно исследователи и сосредоточивают внимание, вторая связана с таким многогранным качеством человека, как человечность, которая реализуется и в практической, и в духовной жизни. Человечности отводится нередко второстепенная роль, и только в религиозном чувстве это свойство обретает определяющее значение.

Ключевые слова: духовное бытие, человечность, ощущения, репрезентанты, чувства, религиозное чувство.

\section{References}

1. Moszhilin S. I. Kaprizy pamyati (Caprices of memory). Filosofskie nauki (Philosophical sciences), 2013,no. 3, pp. 151-157.

2. Malyshkin E. V. Dve metafory pamyati (Two metaphors of memory). St.-Petersburg, 2011. 246 p.

3. Plato. Theaetetus, $191 \mathrm{c}-\mathrm{d}$. Platonis. Opera: in 5 vol. Ed. By J. Burnet. Oxford,1900. Vol. I. 313 p. (Russ. ed.: Platon. Soch.: v 4 t. Moscow, 1993, vol. 2, pp. 192-275).

4. Leibniz G. W. Monadologia. Die philosophischen Schriften von Gottfrid Wilhelm Leibniz: in 7 Bd. Ed. by C. I. Gerhardt. Berlin, 1885, vol. 6, pp. 607-623 (Russ. ed.: Leibniz G. V. Soch.: v 4 t. Moscow, 1982. T. 1, pp. 413-429.)

5. Pushkin A. S. Evgeniy Onegin. Moscow, 1981. 255 p.

6. S. Aurelii Augustini Confessiones. Ed. by M. Dubois, E. B. Pusey. Oxford; London, 1838. 288 p. (Russ. ed. : Augustin Aureliy. Ispoved. Moscow, 1991. 488 p.)

7. Descartes R. Meditationes de prima philosophia. Oeuvres: in 12 vol. Ed. by Ch. Adam and P. Tannery. Paris, 1905. Vol. 7. 612 p. (Rus. ed.: Razmyshleniia o pervoi filosofii. Dekart R. Soch.: v 2 t. Moscow, 1994. T. 2, pp. 3-72.)

8. Pogonyaylo A. G. Istoriya i definitsiya (k voprosu ob istoricheskikh formakh filosofii) (History and definition \{on question about historical forms of philosophy\}). Filosofia istorii filosofii: obyazatelnost $i$ navyazchivost istoricheskogo (The philosophy of history of philosophy: on obligation and obtrusiveness of history). Ed. by E. V. Malyshkin. St.-Petersburg, 2012, pp. 33-49.

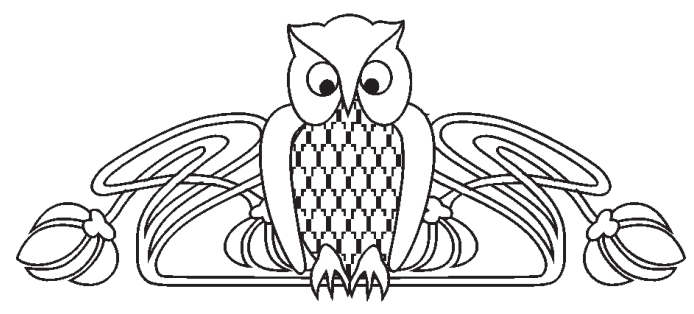

Дефицит человечности, укореняющийся в нашей стране с утверждением рыночных отношений, стал привлекать все большее внимание отечественных исследователей. Весьма характерным и даже символическим представляется название сравнительно недавно опубликованной монографии философа Г. К. Сайкиной «Трудно быть человеком...» [1]. Включаясь в рассмотрение этой темы, мы исходим из того, что, прежде всего, важно выяснить, возможно ли в многообразии смыслов, вкладываемых в понятия «духовное бытие», «духовная сфера», найти нечто общее. 
Ключевым моментом в этом выяснении является анализ ощуцщений и восприятий как исходных компонентов познавательного процесса. Это обусловлено тем, что ощущения представляют собой единство объективного и субъективного: субъективного не как содержательно-противоположного первому, а как им обусловленного, но организованного так, чтобы относительно самостоятельная жизнеспособная система могла выборочно реагировать на внешние воздействия объективного мира как благоприятные, необходимые для ее бытия, так и неблагоприятные, грозящие ее существованию. Эта субъективная оценка является важнейшей характеристикой ощущений и восприятий как способов связи внутреннего бытия живых систем с внешним миром. Субъективность выступает характеристикой, индивидуальной оценкой объективных воздействий на организм, что определяется его организацией, которая представляет собой степень приспособленности данного организма к окружающим условиям и структурно, и функционально, т.е. субъективность - это выражение отношения организма к воздействующим объективным факторам. Одно и то же воздействие будет оцениваться разными организмами существенно различно. Так, скажем, горячее солнце пустыни, благотворное для ее обитателей, неприемлемо для организмов северных районов и наоборот. И эта субъективная приспособленность выражается, прежде всего, в ощущениях, которые выступают как представленности, репрезентанты внешнего во внутреннем. Именно с них начинается вся жизнедеятельность организмов, заключающая в себе одновременно две функции - информативную как способность организма воспринимать внешние воздействия и репрезентировать их в виде накопленного опыта, и оценочную, определяющую соответствие внешних воздействий структуре организма с точки зрения благоприятности/неблагоприятности для его жизнедеятельности. Эта индивидуальная оценка уже на уровне ощущений выступает как субъективность, являясь основой и для субъективности на интеллектуальном уровне.

Эта двойственная функция ощущений и восприятий (о последних как канале связи организма с окружающим миром далее специально говорить не будем) определяет единство познавательной деятельности человека и его эмоционально оценочного отношения к происходящим процессам, что обеспечивает не только целостность всех психических внешних воздействий, но их органическую связь с внешним миром. Как справедливо показывает М. Мерло-Понти, основательно занимавшийся проблемами связи внутреннего и внешнего, «я сам есть не серия психических актов и не стоящее в центре Я, которое объединяет эти акты в синтетическое единство, но уникальный опыт, который невозможно отделить от него самого» [2, с. 517]. Как он поясняет далее, Я - это опыт, который даже во сне определяет возможность «видеть или не видеть, чувствовать или не чувствовать, страдать или быть счастливым, мыслить или отдыхать, одним словом, “объясняться” с миром» $[2$, c. 516]. И невозможно с ним не согласиться в том, что это синтезирующее отношение к миру нельзя связывать только с сознанием. Последнее вступает в отношения к вещам лишь посредством тела. Нам представляется чрезвычайно важным такое понимание сознания и его связи с телом для осмысления не только единства познавательного процесса с эмоциональным отношением к миру, но и целостности всего внутреннего мира человека. Тело, телесность, с этой точки зрения, выступают как особый способ бытия, включая и традиционно понимаемое сознание, и то, что входит в понятие «душа». Такое широкое осмысление тела дает возможность утверждать, что подлинным субъектом является именно тело, когда «собственное тело < ..> составляет вместе с миром единую систему» [2, с. 261].

Слитность тела и пространства Мерло-Понти показывает на примере интеграции пространства окружающей среды в телесное пространство при обучении печатанию на машинке. «Человек, который учится печатать, - пишет Мерло-Понти, - интегрирует пространство в свое телесное пространство» [2, с. 194]. В результате такой интеграции внешнего во внутреннее осуществляется единство объективного и субъективного, благодаря чему явления внутренней жизни человека, выражаемые в понятиях «дух», «душа», «духовность», которые достаточно неопределенны и могут трактоваться далеко не однозначно, в своей основе имеют общие интенции, восходящие к единству информационной и оценочно-эмоциональной функции ощущений как исходящей связи субъекта с окружающим миром.

Ощущения - это такие репрезентанты окружающего мира во внутреннем бытии человека, которые представляют собой единство информационно-объективного фактора и его субъективной оценки, зависящей от системной организации субъекта, его социального и культурного опыта. Это и обусловливает различие в оценках знаний, сведений, которые основываются на информационной функции ощущений. Такая раздвоенность функций познавательного процесса в целом обусловливает возникновение трудностей в нем, преодолеваемых только в дли- 
тельном историческом развитии самого процесса познания, что существенно отличает человеческое познание от технических моделей обработки информации, в которых оценочный фактор если и присутствует, то не играет значительной роли. В постижении же действительности человеком оценочный компонент выполняет в нем не менее значительную роль, чем информационный. А обусловлено это тем, что у человека бытие двойственно по существу: его бытие как живого организма во внешней среде и бытие его «внутреннего мира», представляющее собой единство всех переживаний и размышлений, которые индивидом осознаются. И это «внутреннее бытие» для него не менее интересно и важно, чем информационная сторона взаимодействия с окружающим миром, дающая знание о его свойствах и закономерностях. Именно этим интересом к «внутреннему миру» информативно перерабатывающая сторона бытия человека отличает его от технических систем обработки информации.

Наличие оценивающего фактора во взаимодействии человека с миром играет для него и негативную, и позитивную роли. Первая заключается в возможном противопоставлении субъективного объективному, что может создавать значительные сложности в познании человеком окружающего мира. Положительная же роль определяется целевым назначением оценочного фактора в самоорганизации человеческого бытия. Смысл оценивающей функции во взаимодействии человека с окружающем миром заключается в сохранении этого бытия. И здесь без субъективной оценки как внешних воздействий, так и внутренних переживаний обойтись невозможно - в силу единства «внутреннего мира», в том числе осознания этих переживаний, которые могут не только нести негативную оценивающую информацию, как, например, состояние ужаса, но и быть положительным стимулятором в жизнедеятельности человека, порождая вдохновение, уверенность и другие факторы его поведения.

Сложность познания внутреннего мира человека начинается с того, что сам познавательный процесс внешнего мира является составляющей внутреннего бытия человека. Построение мысленной картины мира на основе ощущений и восприятий как репрезентантов, как представленностей внешнего мира во внутреннем, но в иной - нематериальной - форме, как отмечал еще Дж. Беркли, удваивает мир в бытии человека - на окружающий материальный и мир опыта как единство чувственных и обобщающих абстрактных форм, которые не обладают сугубо своей содержательностью, а заключают в себе содержательность внешнего мира. Но последняя представлена в актах осознания человеком внешнего мира лишь в качестве значений без непосредственной данности сознанию материального носителя знака, каковым выступают нервные процессы. Представленность таких значений внешнего мира во внутреннем осуществляется у человека как в виде чувственных форм, начиная с ощущений, так и абстрактных обобщающих - понятий. Они к тому же обогащаются эмоциональной оценкой, о чем говорилось выше в аспекте оценки внешних воздействий для существования организмов. Однако индивиду интересны и свои собственные переживания, например, когда он слушает трагическую музыку или восхищается красотой произведения искусства, то есть когда его интерес связан с эмоциональным богатством его внутреннего мира, его гармоничности или, напротив, противоречивости. И в этой целостности своего эмоционального состояния, понятийного знания, размышлений и мировоззренческих синтезирующих идей важно выделить определяющие структурные компоненты этого единства.

Прежде всего, в данной целостности следует выделить цуенностные установки, наиболее близкие к сфере практической деятельности людей и непосредственно определяющие их поведение. Они являются результатом синтеза всего жизненного опыта индивида, включая и его мировоззренческие представления, выражающие и отношения человека к миру в целом, и его место в нем, в силу чего они выступают основой деятельности человека. Но само по себе мировоззренческое знание не реализуется в ней. Это осуществляется через психологические установки, среди которых на первом месте - нравственные. Этическая сфера - результат взаимодействия между людьми, и начала она формироваться в процессе становления человека. Значимость выражения доброжелательных отношений в трудовом процессе становящегося человека была настолько велика, что без этого фактора было бы невозможно само его выживание. Нравственные отношения - это отношения к другому как самому себе, это выражение отношения каждого индивида к целостному единству, без которого он просто не существует. И потому сфера нравственных отношений - суть человеческих отношений. Человеческое в человеке - прежде всего нравственное. Отсутствие нравственных отношений, которые по своей сути могут быть только положительными, - это уже деградация человеческой личности, которая может обладать большими знаниями и развитым мышлением, но, лишенная высоких нравственных принципов, она теряет свое главное качество - человечность. Это - превращение человека в механическое су- 
щество, машину. И осмысление духовного бытия человека неразрывно связано с этим качеством.

Здесь следует обратиться к такому выражению субъективности, как религиозное чувство, начавшему формироваться на стадии становления человечества, когда древний человек, используя элементарный и в то же время фундаментальный прием познания - понимание, достигаемое путем сопоставления нового с уже понятным, стал наделять явления внешнего мира свойством своего внутреннего мира - «душой», что в конечном счете послужило базой для представлений о мире богов. Значительный вклад в осмысление религиозного чувства внес К. Юнг. Исходя из естественно-научного ви́дения мира, он убедительно показал, опираясь на психоаналитические исследования, что значительную роль в жизни человека играет архетипический образ божества. Он означает лишь существование древнего образа, «который, - пишет Юнг, $-<\ldots>$ представляет собой наибольшее, что мы с психологической точки зрения можем сказать о Боге» [3, с. 164]. Существенно важным при этом, по Юнгу, становится то, что вера в такой образ не только позволяет человеку излечиться от невроза, но и помогает в его бытии в целом, отмечая при этом, что «речь идет не о вере, а об опыте, который абсолютен. Можно ли найти лучшую истину о первоосновах бытия, вопрошает Юнг, - нежели та, которая помогает тебе жить» [3, с. 165].

О практической значимости верования человека в высшее духовное существо много пишет и сторонник прагматической философии У. Джеймс. Исследуя религиозный опыт, он понимает религию как такую духовную сферу, которая, постигая реальность невидимого, имеет большое значение для практической жизни человека, поскольку она опирается не столько на рациональную, сколько на чувственную сторону осознания человеком мира. Для разума такие понятия, как «душа», «Бог» и т.П., замечает Джеймс, не содержат в себе сколько-нибудь отчетливого «чувственного содержания», в практическом же отношении они заключают важный смысл. Если наука фактически безразлична к внутреннему, сокровенному опыту индивида, то религия позволяет сохранить человеку и внутреннее спокойствие, и убежденность в своей жизненной позиции, и (здесь Джеймс согласен с Юнгом) даже здоровье, поскольку первопричиной любой болезни, по Джеймсу, является, в конечном счете, оторванность данного человека от Бога.

При этом американский философ обращается к опыту Л. Толстого, переживавшего душевный кризис в течение двух лет, закончившийся переосмыслением его жизненной позиции, что выразилось в утверждении, на которое ссылается Джеймс: «Знать Бога и жить - одно и то же. Бог есть жизнь» [4, с. 148].

Такая значимость духовного мира верующего человека связана с первостепенным интересом его как личности не к «устройству» окружающего мира, а к своему внутреннему бытию, которое служит исходным фактом его размышлений о «природе» и сущности окружающего мира в целом.

Эта исходность интересов такого типа личности особенно ясно высказана М. Бубером и заключается в том, что главным словом, выражающим существо человека, является слово «ЯТы», что означает невозможность его бытия вне связи с Богом, т.е. факт существования человека в двух мирах - внешнем, в который он погружен как природное существо, и внутреннем - лежит в основе приоритетного интереса разных людей то к устройству внешнего мира, что связано в конечном счете с практическими целями, а то - к своему внутреннему миру. И можно полагать, что определяющий характер интереса того или иного индивида к этим мирам и служит, соответственно, основой формирования двух типов личностей - интровертов и экстравертов. У последнего типа познавательный интерес сосредоточивается на внешних объектах, в том числе желании общения с другими людьми, и отчетливо проявляется у лиц, занимающихся научной деятельностью. Результатом интеллектуальных усилий такой личности становится формирование естественной картины мира. Будучи связанной с эмоциональной сферой, такая мыслительная деятельность личности создает свой богатый внутренний мир, в котором основой является знание, причем, прежде всего, о внешнем, объективном мире. Однако это - не «массовый» вариант духовной жизни личности. У основной массы людей интерес к внешнему миру, его познанию связан с практической жизнью, и в таком случае сфера знания становится более ограниченной, причем в значительной мере связанной с практическими взаимоотношениями людей, оставаясь основой всего внутреннего мира такого индивида. При этом у людей такого типа, будь то научный работник, организатор, бизнесмен, нравственная сфера не привлекает пристального, тем более первостепенного внимания. И это отношение к своему нравственному облику ведет к формированию у них массы оправдательных принципов, начиная с таких, как «все средства хороши для достижения цели», что обедняет духовный мир человека мыслящего. Даже если не обращаться к фактам, свидетельствующим о том, что в мире 
существуют «злые гении», то все же следует подчеркнуть: отсутствие у человека развитых нравственных, собственно человеческих начал сближает его с вычислительными машинами, успешно соперничающими с человеком в сфере обработки информации, но не способными понять духовный мир другого и, возможно, посочувствовать этому другому.

Субъективность приобретает особое значение в формировании религиозного чувства и, соответственно, религиозного мировоззрения. Картина мира, сформированная у человека под влиянием субъективности религиозного чувства, имеет свои особенности, по сравнению с ее оформлением на основе естественно-научных фактов, обладая определенными преимуществами и недостатками. И главное из преимуществ такого ви́дения состоит в том, что в этом случае концентрируется первостепенное внимание на определяющем качестве человека - его человечности, обобщенно выражающем нравственное отношение, органично связанное с доброжелательностью и любовью. Это качество, формируемое на основе образа Бога и Его заповедей, становится для индивида главным, определяя все его поведение и даже позволяя преодолеть в определенных условиях инстинкты во имя торжества Божественного начала в человеке, с точки зрения верующего, а фактически - человечности в человеке. Важность этого становится особенно ясной на фоне понимания безразличного отношения мира к судьбе человека, которое М. Хайдеггер выразил в понятии «заброшенности». Человек заброшен в этот мир, и лучшее, что он может делать в нем, - бороться со всеми вытекающими возможными последствиями: или побеждать и быть «царем»- царем природы и своих сограждан, или быть побежденным. Человечность, воспитываемая на фактах жизни, в реальном процессе существенно, в лучшем случае, оказывается весьма ограниченной. Так что религиозное чувство является значимым фактором в воспитании в человеке человечности, причем нередко более эффективным, чем это осуществляется в пространстве естественно-научного мировоззрения. И светской власти следует консолидировать свои, пока очень слабые, усилия с возможностями религии для укрепления в бытии человека нравственных ценностей, не противопоставляя религиозное и естественнонаучное ви́дения мира, что было свойственно советской власти, так чтобы главным мерилом цивилизованности общества был не только научный и технический прогресс, который может вызывать у человека притязания на всесилие, но и степень развития человечности как высшего качества, проявляемого в высокой нравственности, доброжелательности, любви и созидающем творчестве. Подводя итог, можно сказать, что тем общим, что присуще понятиям «духовное бытие» и «духовный мир» человека, которые могут истолковываться различным образом, особенно в пространствах таких разных мировоззрений, как естественно-научное и религиозное, является наличие в них смысла, который выражается в слове «человечность».

Таким образом, анализ духовного мира человека приводит нас к мысли о том, что главное в нем не знания, служащие основой созидания такой техники, которая потрясла бы воображение человека, жившего всего полвека назад. Главное в нем - свойство «быть человеком», и оно должно быть в центре внимания человечества, а не восхищение тем, что тело постчеловека, который, по мнению А. Г. Дугина, уже приходит на смену современному человеку, и он «постепенно превращается в искусственный протез, бесконечную серию протезов, позволяющих продлевать тела до бесконечности. Субъект и его тело подвергаются трансмутации в гиперпродуктивной модели клона-двойника. Двойник - таков совершенный протез, симулякр тела» [5, с. 169]. Но размышлять о постчеловеке, который со временем превратится в симулякр тела, к сожалению, проще, чем найти фундаментальное основание для утверждения в человеке человечности.

\section{Список литературы}

1. Сайкина Г. К. Трудно быть человеком... Метафизические маршруты человека. Казань, 2012. 428 с.

2. Мерло-Понти М. Феноменология восприятия. СПб., 1999. $606 \mathrm{c}$.

3. Гловер Э. Фрейд или Юнг. СПб., 1999. 206 с.

4. Джеймс У. Многообразие религиозного опыта. М., 1993. $432 \mathrm{c}$.

5. Дугин А. Г. Постфилософия. Три парадигмы в истории мысли. М., 2009. 704 с.

\section{Humanity as the Expression of the Spiritual Existence of Human}

\section{B. I. Mokin}

Saratov State University

83, Astrakhanskaya str., Saratov, 410012, Russia

E-mail: boris.mokin2014@yandex.ru

The subject of analysis in the article is senses, which are examined as representing the external world in the interior human existence. For that reason they are not only the basis of human perception, as it is believed by many scientists, but they are also the basis of the whole spiritual existence. Senses possess informational and appreciating functions. 
The former determines the sphere of knowledge (which traditionally attracts scientists' attention), while the latter is connected with humanity, which is a very many-sided quality and which is implemented both in spiritual and practical life. The humanity is often conferred to a background role and only in religion it becomes a determining quality. Key words: spiritual existence, humanity, senses, feelings, religious feeling.

\section{References}

1. Saykina G. K. Trudno byt chelovekom... Metafizicheskie marchruty cheloveka (Hard to be a human... Metaphysical routes of human). Kazan, 2012. 428 p.
2. Merleau-Ponty M. Phénoménologie de la perception. Paris, 1945. 466 p. (Russ. ed.: Fenomenologiya vospriyatiya. St.-Petersburg, 1999. 606 p.).

3. Glover E. Freud or Jung. London, 1950. 207 p. (Russ. ed.: Glover E. Freyd ili Yung. St.- Petersburg, 1999. 202 p.).

4. James W. The Varieties of Religious Experience. A Study of Human Nature. New York; London; Bombay, 1902. 596 p. (Russ. ed.: Dzheyms U. Mnogoobrazie religioznogo opyta. Moskow, 1993. 432 p.).

5. Dugin A. G. Postphilosophiya. Tri paradigmy v istorii mysli (Postphilosophy. The three paradigms in the history of thought). Moskow, 2009. 704 p.

\section{ТОЛЕРАНТНОСТЬ И ДИСКУРСИВНАЯ ВЛАСТЬ}

Парфенов Александр Игоревич -

кандидат философских наук,

доцент кафедры философии культуры и культурологии,

Саратовский государственный университет

E-mail: anteater1@yandex.ru

Статья посвящена критике современной концепции «толерантности». Исследуется дискурс о толерантности как средство власти, выявляются негативные последствия идеологии «политкорректности». Идея "толерантности» стала программой, которая агрессивно внедряется в сознание объектов идеологического воздействия с целью уничтожения ментальных основ сопротивления гегемонии западной цивилизационной модели. Концепция толерантности используется как механизм подавления свободомыслия и препятствие развитию критического мышления. В качестве замены традиционной морали «толерантность» способствует деградации человека, вместе с тем не исключается и конструктивный потенциал толерантности.

Ключевые слова: толерантность, политкорректность, идеология, дискурс, гендер, идеология.

Понятие «толерантности» в последние годы прочно вошло в обиход отечественных СМИ, о толерантности как о положительной ценности писали статьи, книги и даже учебники. Политический дискурс становился все более политкорректным, как это принято на Западе, и многие отечественные полемисты были готовы принести в жертву на алтарь толерантности собственные мысли и убеждения. Новое направление в трактовке данного явления, по всей видимости, придаст недавнее послание Президента Федеральному Собранию (2013). Президент говорил о России как о великой стране «с многовековым опытом не так называемой толерантности, бесполой и бесплодной, а именно совместной, органичной жизни разных народов в рамках одного единого государства» [1].

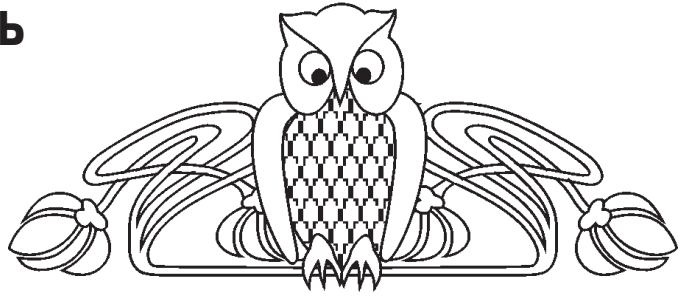

Проект толерантности стал базовым для западной цивилизации (преимущественно для Европы, США и Канады) и был реализован в нескольких направлениях: в политике мультикультурализма (культурной толерантности), политкорректности (толерантности дискурсивных практик) и ЛГБТ-толерирования (равноправия сексуальных меньшинств). На практике толерантность сообразно западной политической стратегии, вопреки декларируемым определениям, заключается в беспрекословном подчинении всякого социума определенным правовым стандартам, в отказе от национальных интересов в угоду идентичности идеальному конструкту - так называемому «мировому сообществу». Можно наряжаться в национальный костюм и петь народные песни, это приветствуется, это «толерантно», возможно, даже суровый сенатор Дж. Маккейн прольет слезу умиления, глядя на кокошник или иной атрибут «русского стиля». Но национальная идентичность допустима только на уровне эстетики, как модно говорить - «этники», в правовых, политических, экономических вопросах все обязаны подчиняться установленным правилам. Данная политика в совокупности с иными формами принуждения в состоянии поставить то или иное государство в условия внешнего управления, но даже такой симбиотический уровень интеграции в «мировое сообщество» вовсе не гарантирует ни повышения уровня жизни, ни уверенности в завтрашнем 